\title{
Safety institutes urge better bar-coding of drugs
}

Published at www.cmaj.ca on Feb. 12

I mproved bar-coding of all drugs and standardization of bar-coding would significantly reduce medication errors and save lives, say the Institute of Safe Medication Practices Canada (ISMP Canada) and the Canadian Patient Safety Institute.

To that end, the institutes have launched an initiative to encourage all pharmaceutical companies to use GS1 bar codes on all levels of drug packaging.

But the measure is strictly voluntary and would likely take years to implement, says David U, president and chief executive officer for ISMP Canada.

While GS1 bar codes are already used by most pharmaceutical companies in Canada, they are typically applied only to the exterior packaging of drugs.

Bar-coding is generally not applied to the interior packaging of bulk purchases made by hospitals and other health care facilities. So when staff remove drugs from cases, they often don't have a bar code, and facilities often don't have a system for applying bar code on those drugs.

The upshot is a highly checkerboard system within Canada that the institutes argue contributes to the high incidence of medication error, which is estimated to be responsible for as much of $24 \%$ of preventable adverse events, including death, (CMAJ 2004;170[11]:1678-86).

Putting bar codes on the interior packaging of pharmaceuticals in Canada is the first step of the initiative, says Sylvia Hyland, vice-president of ISMP Canada.

All bar codes would include a drug's identification number, commonly called the GTIN, which identifies the product, brand name and packaging size, says GS1 Canada, a firm working with ISPM Canada and the Canadian Patient Safety Institute to develop the initiative. It is hoped that bar codes will eventually include the drug's expiry date and batch number.

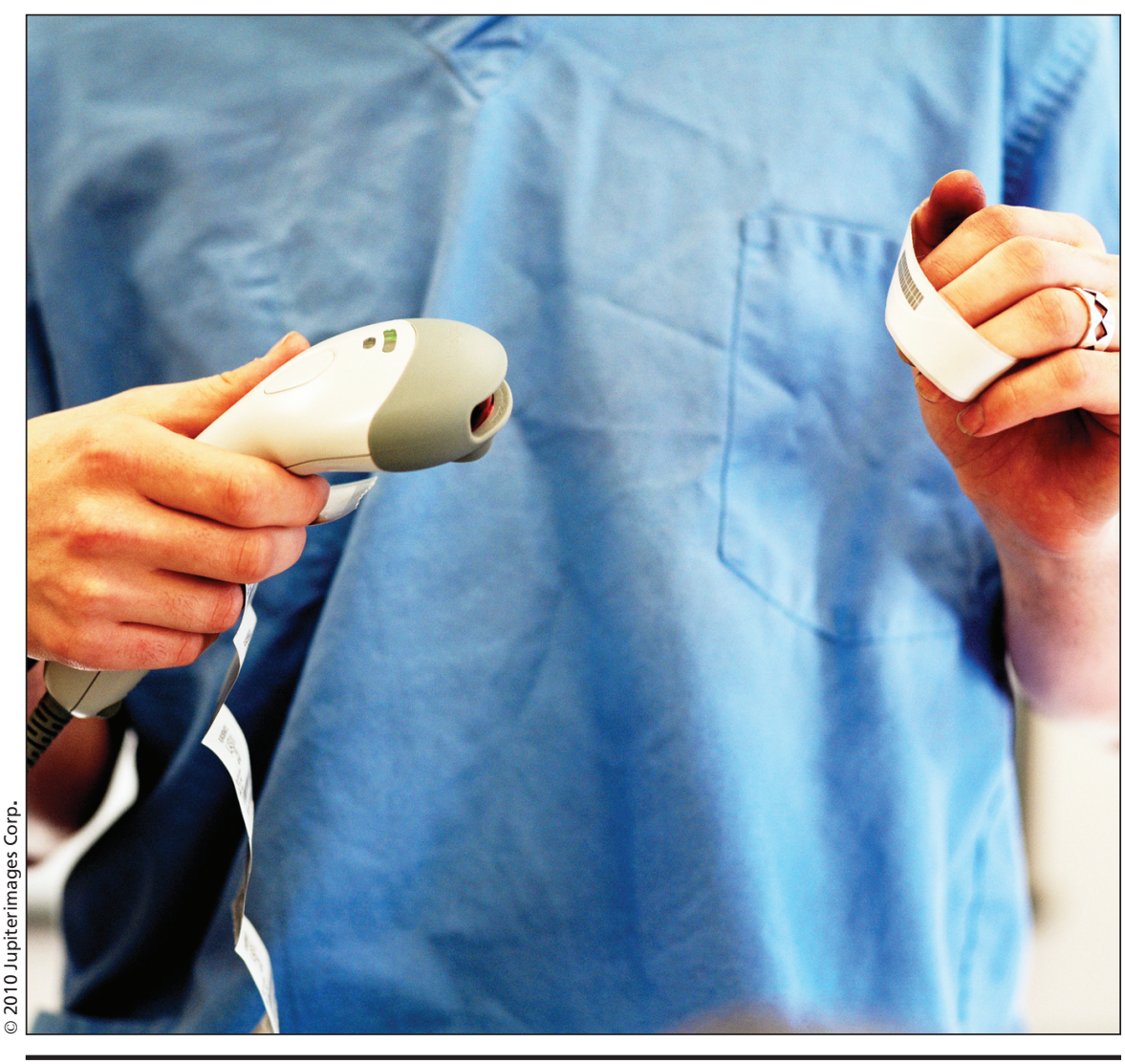

Proponents of bar-coding drugs say they'd ultimately like to see the creation of a system in which patients' medical bracelets are coded with information about their medications.

Hyland argues that bar codes need to be included on ampoules and vials because problems occur in hospitals once unit dose packages are removed from their larger casings. "It sounds like a small change but really it's a big change. There are so many drugs. This system will prevent mistakes with medication from reaching patients."

Currently, bar-coding is widely utilized in the United States. But there's a significant variation across Canada in the manner in which health facilities utilize bar codes, says Pierrette Leonard, senior adviser (national partners), for the Canadian Patient Safety Institute. Some hospitals have their own systems, but it is not uniform, she says.

Ultimately, proponents hope, the system could be reinforced by bar-cod- ing patients' medical bracelets with information about their medications.

"The product will be scanned into the pharmacy, scanned again when it goes out onto the floor and again by the nurses to check that it matches their medical administration records," says Hyland. "Then the nurse can scan the patient's bar code to make sure the right medication is being given to the right patient."

But that will depend upon the full introduction of electronic health records within Canadian health care, Hyland says.

The proposed system would also depend on hospital cooperation, says David U. "It is not a simple chore. In order to do bedside scanning, we need sophisticated infrastructure put in place." 
But even if bar-coding systems are developed to reduce medication errors in hospitals, they might generate more problems, says Ross Koppel, a sociologist at the University of Pennsylvania in Philadelphia, who studied the use of bar codes in five American hospitals.

Medical bar-coding systems have the potential to increase patient safety, but only if they are supplemented by constant on-the-floor analysis, vigilance and repair, Koppel says. But sometimes the codes are so torn, ripped or sodden they can't be read by scanners. In Koppel's experience, nurses were sometimes unable to scan the codes properly so they developed flawed techniques to work around the problem.

"To be effective, these problems have to be addressed. Those who view it as a labour-saving measure will be sorely disappointed," says Koppel. "It is a reasonable idea, but in reality, it is much more messy and complex."

Bar-coding is also expensive, not only in terms of the infrastructure required to implement it, but also in terms of the labour needed to maintain the system, he warns. "It's not cheap. Hospitals will have to budget for it." Brittany Hinds, Ottawa, Ont.

DOI:10.1503/cmaj.109-3182 